\title{
Laser Via Generation into Flexible Substrates
}

\author{
Zsolt Illyefalvi-Vitéz*, Richárd Berényi*, Péter Gordon*, János Pinkola*, \\ Miklós Ruszinkó* and Jan Vanfleteren** \\ *Budapest University of Technology and Economics, Department of Electronics Technology \\ Goldman t. 3, Budapest, H-1111, Hungary \\ **IMEC \& Universiteit Gent \\ St.-Pietersnieuwstraat 41, Gent, B-9000, Belgium
}

\begin{abstract}
The microelectronics industry is moving toward smaller feature sizes. The main driving forces are to improve performance and to lower cost. From the performance point of view the small distances between chips together with the short interconnection routes have of great importance in order to achieve faster operation. The application of polymeric materials for the insulating and protective layers of interconnect substrates is beneficial to the performance and to the cost of a circuit module as well. An advanced technology for the fabrication of very high density interconnects applies microvia flexible substrates. This technology has particular significance for the interposers of chip scale packages.
\end{abstract}

Abstract

\section{Introduction}

$\mathrm{CO}_{2}$ and $\mathrm{Nd}: Y A G$ lasers are the most commonly used equipment for laser processing applications. The differences between the beam properties and quality of the two laser types and the various material interactions strongly determine their applicability fields. The wavelength of the beam produced by a $\mathrm{CO}_{2}$ laser is about $10 \mu \mathrm{m}$, which is absorbed well by plastics, wood, paper and organics. The glass is opaque at this wavelength as well. Apart from the fact that metals nearly act like mirrors and absorb only a few percent of the medium-IR beam, sheet-metal cutting and welding is the largest market for $\mathrm{CO}_{2}$ laser processing systems: about 20,000 systems have been installed for this application worldwide. This is thanks to the high continuous (average) output power of $\mathrm{CO}_{2}$ lasers.
Laser processing of polymeric materials applied for via generation, image transfer, contour cutting, etc. has proved to be an efficient tool for the fabrication of interconnect substrates. The paper describes some results of a research project that aims at the application of $\mathrm{CO}_{2}$ and frequency multiplied $\mathrm{Nd}$ :YAG lasers for drilling via holes into copper clad flexible laminates of polyimide, epoxy and polyester base materials. The effect of the application of an interfacing (adhesive) layer is also the topic of the investigations. The physics of processing using a wavelength range from the far infrared radiation of the $\mathrm{CO}_{2}$ laser till the UV wavelengths of frequency quadrupled Nd:YAG lasers are considered to be modeled, examined and evaluated.

The low average power of Nd:YAG lasers working in pulsed mode gives low cutting and welding speed, but it still has a significant advantage: their high energy pulses can overcome the surface reflectance of most materials, thus providing effective drilling, engraving and other processes.

How can $\mathrm{CO}_{2}$ lasers be used effectively, if metals are so reflective at $10.6 \mu \mathrm{m}$ ? If the laser is powerful enough (from a few hundred watts up to the 10 kilowatts order), the fraction of the focused beam that is absorbed by the thin upper surface layer turns into heat and produces a little molten point, that absorbs much better at this wavelength. Microseconds after this point is formed, a little hole with molten walls will develop through the metal. Moving the beam and thus the hole in the metal will produce a narrow cut, and kerf widths just like $50 \mu \mathrm{m}$ can also be performed [1-3]. 


\section{The applied $\mathrm{CO}_{2}$ laser processing system}

The processing system of the Department [4] is based on a $25 \mathrm{~W} \mathrm{CO}_{2}$ laser manufactured by the Synrad Company [5]. The beam emitted by this laser is focused in a $100-200 \mu \mathrm{m}$ spot. The power density in this spot is not enough to produce the molten point on metals, but it is sufficient for cutting and drilling plastics, plexiglass, of course paper, different types of polymer foils and many other materials.

The Department's $\mathrm{CO}_{2}$ laser is controlled by a PWM (pulse width modulated) TTL signal, that contains the information of the required output power. The smaller the duty cycle, the less power the laser will emit. To stop lasing, the duty cycle has to be reduced to a given value, but mustn't be decreased to $0 \%$, thus retaining the plasma state in the lasing volume [5]. Our control card can produce this signal and also supports some processing technologies, e.g. controlling the drilling time by hardware with the built-in micro-controllers. It can monitor the status of the laser as well, and inform the operator through the software if a system parameter is out of its normal interval. With the D/A converter of the card the laser can be computer-controlled with its own manual controller too.

When designing the optical system of a $\mathrm{CO}_{2}$ laser processing unit, it should be taken into consideration that the beam of about $10 \mu \mathrm{m}$ wavelength can not be "conducted" through fiber-optic cables, because up till now no suitable material has been found for that function. On the other hand, the Nd:YAG beam can be run through fibers made of common materials. Therefore, a $\mathrm{CO}_{2}$ laser beam can only be delivered by a system of mirrors and lenses. To eliminate the power loss and the overheating of the optical units, the lenses must be transparent at the $10.6 \mu \mathrm{m}$ wavelength. There is not a wide variety of these materials, $\mathrm{ZnSe}$ (Zinc Selenide) and Ge (Germanium) are used generally. We use a $\mathrm{ZnSe}$ focusing lens with a focal length of $50 \mathrm{~mm}$ ( 2 inches).

Finding the proper material for the mirrors is less of a problem. Since gold, silver and copper reflect the most of the $10.6 \mu \mathrm{m}$ beam, they can be used as cover layer on any type of a carrier plate. We used a gilded glass for this function, because it was easy to make with the Department's vacuum evaporation unit.
The realized optical system is shown in Figure 1. The focusing lens is put into a tube that ends in an interchangeable jet with a diameter from $1 \mathrm{~mm}$ to $3 \mathrm{~mm}$. This could also provide the possibility to catalyze the metal cutting by high-pressure oxygen jetting, but we use it just as an air shield: the air streaming out blows the fume away, so that it can't hit the lens.

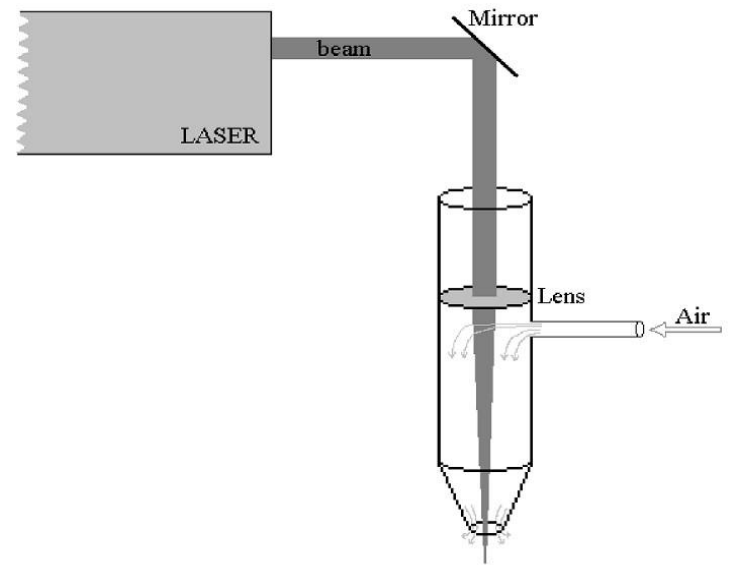

Figure 1. The optical elements

For safety reasons other steps have to be taken as well. $\mathrm{CO}_{2}$ laser processing can be quite dangerous without paying attention to this. Gasassisted metal cutting generates little particles that have a diameter about $1 \mu \mathrm{m}$. This is the worst size to breathe in, as it can easily cause injury of the lung. Welding metals generates intensive UV light, which passes through the eye protecting glasses that were designed for the $10.6 \mu \mathrm{m}$ wavelength. It would also give the operator a suntan or sunburn in the worst case. However, nothing is as bad as processing plastic. The by-products of these processes can include very dangerous materials and gasses [6]. This is why two different methods are used in our system simultaneously to exhaust these materials. One is a common fan that extracts the inner processing volume; the other device is embedded in the moving table.

Figure 2 shows the special design of our moving table. It is always hard to find the right material for the stage that holds the sample to be processed. This material should absorb the most of the remaining part of beam, but it must not get damaged by the heat and must not transmit heat to the sample either. It became obvious that these tasks (holding and heat-absorbing) have to be separated. Thin aluminum plates standing 
vertically hold the sample, and the beam hits the bottom $10 \mathrm{~mm}$ deeper than the sample is. The material of the bottom plate is aluminum as well, that is reflective at 10.6 , but the beam, passing $20 \mathrm{~mm}$ after the focus point, is wider and it can not affect the sample significantly once more. At higher power rates this reflection would not be acceptable.

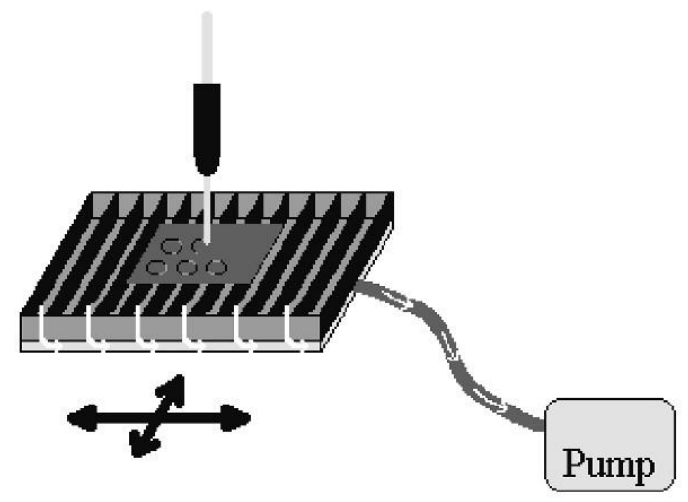

Figure $2 \mathrm{XY}$-table with extracting

As is it was mentioned above, the extracting is embedded in the moving table as well. The table has double-bottom; the space between the lower and the perforated upper plates is exhausted by a vacuum pump, so there is low-pressure between the vertical plates, too. This method also fixes the sample on the table, which is very convenient when prototyping.

The XY-table of our system is based on stepper motors, has a moving resolution of $12.5 \mu \mathrm{m}$ and has at most $25 \mathrm{~mm} / \mathrm{s}$ velocity.

\section{3. $\mathrm{CO}_{2}$ laser processing of flexible substrates}

There is a more than fifteen years tradition at BME-ETT regarding the investigation of laser beam materials processing. A few recent publications of the results are listed in the References [7-9]. Here we are publishing some experiments, which have been performed by our $\mathrm{CO}_{2}$ laser on flexible laminates composed by $35 \mu \mathrm{m}$ copper layer on $120 \mu \mathrm{m}$ thick polyimide foil. The aim of the experiments was to pattern the polyimide foil by selective laser removal.

\subsection{Laser via drilling into polyimide-on- copper foil}

Blind holes were punched by our $\mathrm{CO}_{2}$ laser system into the polyimide foil of flexible substrates. The aim of the experiments was to study the process as the function of the power (in the range of 2,5-25 W) and the duration (ranging from 2 to $20 \mathrm{~ms}$ ) of the radiation. The results are summarized in Figures 3-6.

In Figure 3 the SEM (Scanning Electron Microscopic) photos of the holes are illustrated, with the processing power range of 7,5-17,5 W from left to right, and duration of irradiation of 4-14 ms from bottom to top. It means that the hole in the lower right corner was prepared by $30 \mathrm{~mJ}$ energy, while the hole in the upper left corner was drilled by $245 \mathrm{~mJ}$.

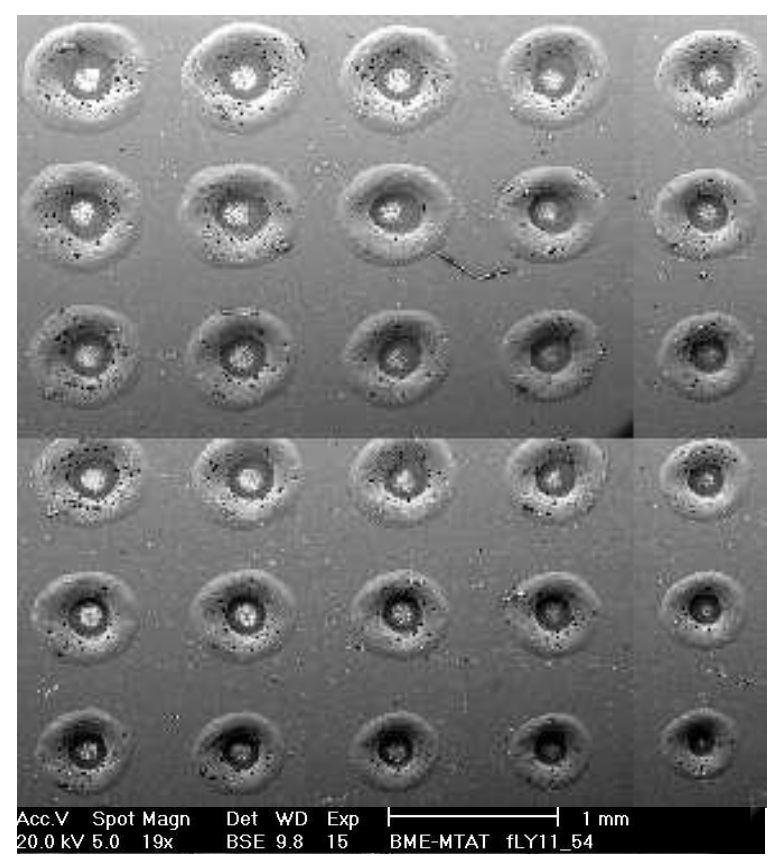

Figure 3 Top view photos of laser drilled blind holes

The hole diameters were measured on these photos and plotted in Figure 4. Always the diameters of the cleaned areas were determined, where - in accordance with visual inspection the polyimide was removed from the copper surface.

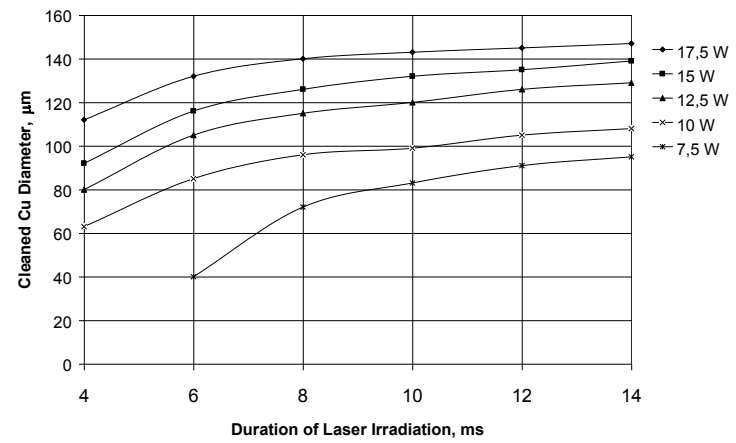

Figure 4 Hole diameters versus of power and time 
There are no clean areas at all below $30 \mathrm{~mJ}$ processing energy. On the other hand, the diameters are growing slowly above a threshold of about $70 \mathrm{~mJ}$, so it is considered as an optimum value.

For example the processing with 7,5 $\mathrm{W}$ and $8 \mathrm{~ms}$ ( $60 \mathrm{~mJ}$ energy) resulted in a hole of about $125 \mu \mathrm{m}$ diameter. Thus the intensity and the energy density could be calculated to 2,4 $\mathrm{kW} / \mathrm{mm}^{2}$, and $4,8 \mathrm{~J} / \mathrm{mm}^{2}$, respectively. A larger photo of this hole and an even larger of its bottom are shown in Figure 5 and Figure 6. On the basis of Figure 6 we can realize, that although the copper can be seen - the polyimide is not removed completely.

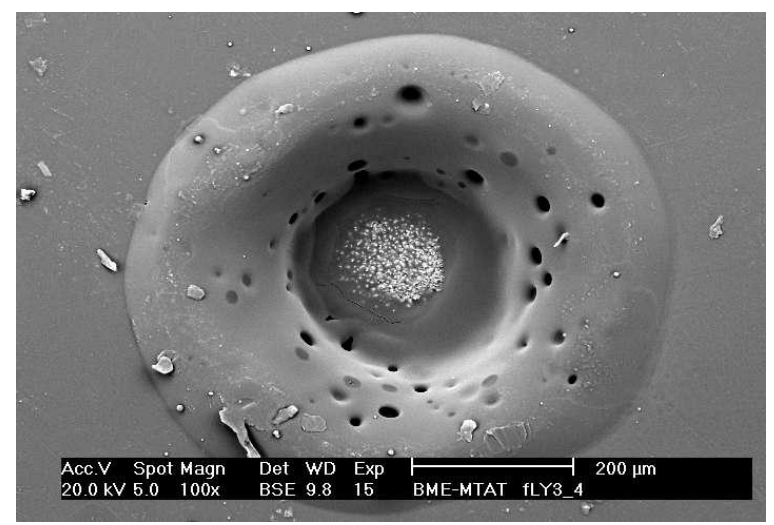

Figure 5 The photo of the 7,5 W - 8 ms hole

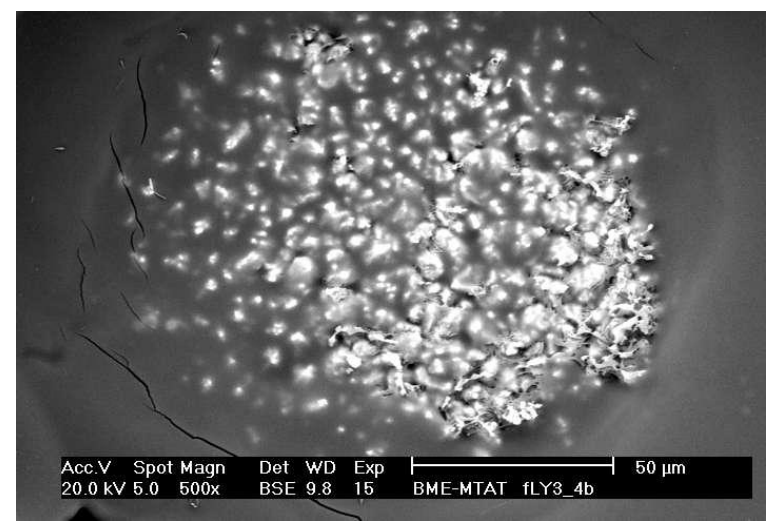

Figure 6 The bottom of the same 7,5 W - 8 ms hole

\subsection{Laser removal of polyimide from the copper foil}

In some cases, e.g. when the inner and outer windows of $\mathrm{TAB}$ substrates are fabricated, it is necessary to remove the polymer foil from a larger area of the copper surface. It can be made by scanning over the required area by the processing laser beam.
When a beam of $0,125 \mathrm{~mm}$ diameter and $5 \mathrm{~W}$ power (i.e. with the intensity of about $0,4 \mathrm{~kW} / \mathrm{mm}^{2}$ ) scans the surface with $10 \mathrm{~mm} / \mathrm{s}$, then the beam irradiates the surface through $12,5 \mathrm{~ms}$. This beam effects the surface with the energy density of $5 \mathrm{~J} / \mathrm{mm}^{2}$. Since the hole of $7,5 \mathrm{~W}-8 \mathrm{~ms}$ was prepared by $4,8 \mathrm{~J} / \mathrm{mm}^{2}$, the two types of processing can be considered as similar, and they are well comparable. For this reason the material removal experiments were prepared by a $5 \mathrm{~W}$ beam scanning with $10 \mathrm{~mm} / \mathrm{s}$ velocity.

On the basis of the hole photos (e.g. that of Figure 5) we can assume that the laser beam melts the polymer material, it begins evaporating, and in this way the beam (and the vapor) pushes away the material rather than ablates it from the surface. We tried to follow the process by scanning across a stripe of flexible substrate running up to and down from it at the edges. The feeding step of the scanning process was $0,025 \mathrm{~mm}$. SEM photo pairs - top view and cross-section-like view of the edge and surface profiles are shown in Figure 7 after the first and the fifth scans. (The distance between the first and fifth scan is $0,1 \mathrm{~mm}$, the beam moved from the right to the left.) The comparison of the edge photos show, that the pushed material on the left side of the kerf became much higher than on the right.
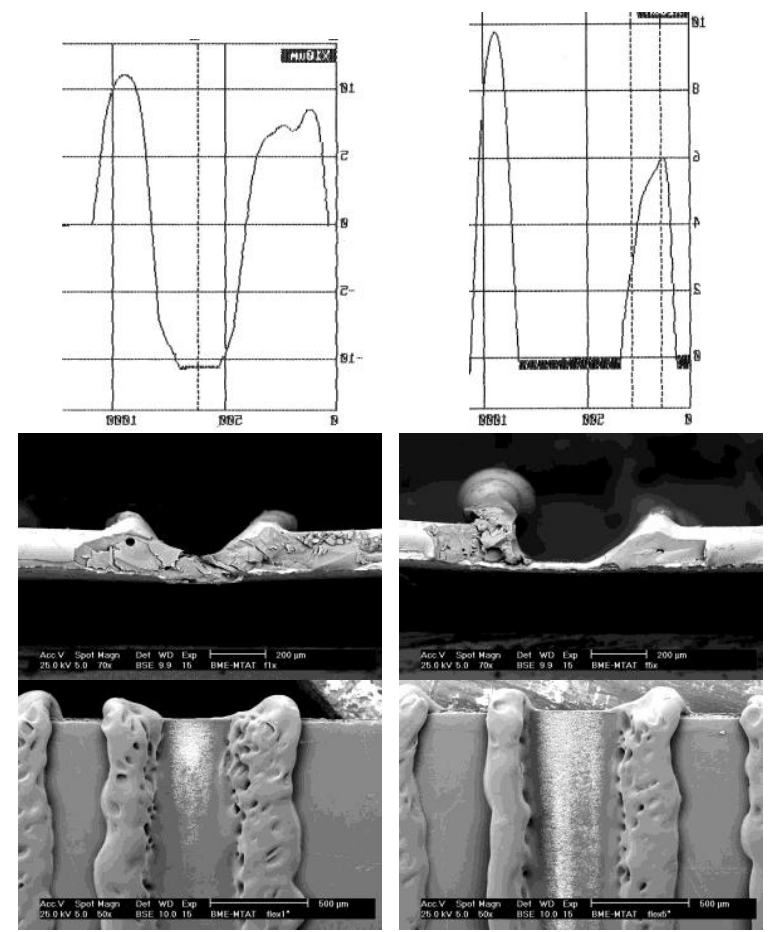

Figure 7 Surface cleaning by laser scanning 


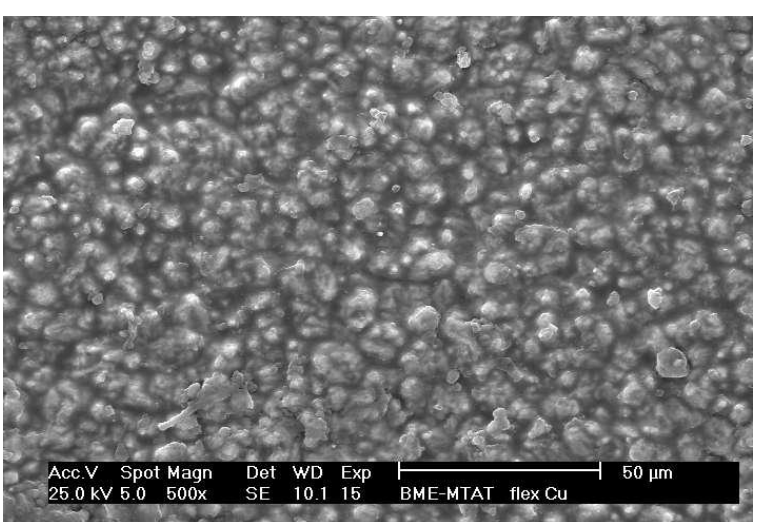

Figure 8 The surface cleaned by $\mathrm{CO}_{2}$ laser scanning

The SEM photo of the same cleaned surface in larger magnification (Figure 8) shows, that a very thin polymer layer remained back on the surface. Materials analyses also proved the presence of the layer by finding high amount of carbon and oxygen on the surface. Some residues of the adhesive were also found.

Processing the surface with a Q-switched Nd:YAG laser definitely improved the surface properties (Figure 9): the pulsed laser beam removed most of the adhesive residues and decreased the amount of the carbon and oxygen, i.e. the residues of the polymer layer. While the surface processed only the $\mathrm{CO}_{2}$ laser remained practically unchanged in comparison with its original structure, the pulsed Nd:YAG laser processing melted and restructured the surface.

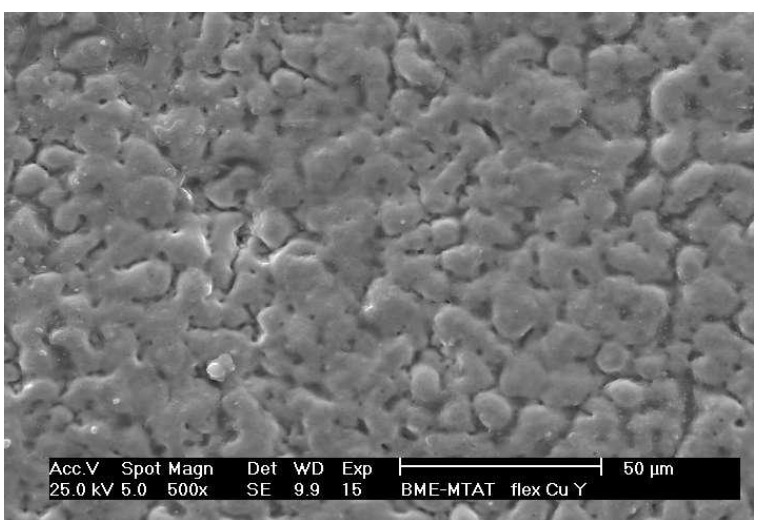

Figure 9 The surface cleanliness improved by Nd:YAG laser post-processing

\section{Conclusions}

Our investigations regarding the removal of the polyimide foil from the surface of the copper layer of flexible laminates have given interesting results: it proved that melting and shifting the material are dominating when using continuous wave scanning for the processing. Further steps, e.g. Nd:YAG laser surface processing, are needed to remove the polymer residues and to decrease the height of the builtup materials along the kerf sides. Processing with other laser types, including $\mathrm{CO}_{2}$ laser with shorter and much higher pulses, should be also tested to find the suitable solution.

\section{References}

1) Belforte D. A., Archives August 1998 - Back to basics: "Laser metal cutting", URL: http://www.laserfocusworld.com

2) Lerner E. J., "Carbon dioxide lasers deliver flexibility and power”, Laser Focus World, Sep 1998, pp.131-137.

3) Harry J. E., "Ipari lézerek és alkalmazásuk”, Müszaki Könyvkiadó, Budapest, 1979, pp.105-106, 140-149, 213

4) Gordon, P.: Development of a $\mathrm{CO}_{2}$ Laser Processing System and Applicability Researches, $22^{\text {nd }}$ International Spring Seminar on Electronics Technology, Freital-Dresden (Germany), May 18-20, 1999, pp.307-310.

5) Series 48 Lasers, “Operation and Service Manual”, SYNRAD Inc. 1998

6) Budd R. W., "Comparison of $\mathrm{CO}_{2}$ and $\mathrm{Nd}$ :YAG lasers for industrial applications", URL: http://plop.phys.cwru.edu/repairfaq/sam/laserco2.htm, December 1998.

7) Illyefalvi-Vitéz,Zs.: Laser Processing of Adhesives and Polymeric Materials for Microelectronics Packaging Applications. $4^{\text {th }}$ International Conference on Adhesive Joining and Coating Technology in Electronics Manufacturing. Espoo, Finland, June 18-21, 2000, pp.289-295.

8) Illyefalvi-Vitéz,Zs.; Pinkola,J.; Ruszinkó,M.; Bojta,P.; Hertel,L.: New MCM-L Structure Applying Packageless Chip Size Devices and Laser Processed Board. The 33rd. International Symposium on Microelectronics (IMAPS 2000), Boston, Massachusetts (USA), September 20-22, 2000, pp.826-831.

9) Illyefalvi-Vitéz,Zs.: Laser processing for microelectronics packaging applications. Microelectronics Reliability, vol.41 (2001), pp.563-570. 